\title{
Структурные особенности биогенного апатита субфоссильных скелетных остатков (черепов и рогов) северного оленя из Арктической зоны Западной Сибири
}

\author{
Рянская А.Д. ${ }^{1}$, Киселева Д.В. ${ }^{1}$, Панкрушина Е.А. ${ }^{1}$, Косинцев П.А. ${ }^{2}$, Бачура О.П. ${ }^{2}$, Гусев А.В. ${ }^{3}$ \\ ${ }^{1}$ Институт геологии и геохимии им. ак. А.Н. Завариикого УрО РАН, Екатеринбург, \\ tosenka2008@gmail.com \\ ${ }^{2}$ Институт экологии растений и животных УрО РАН, Екатеринбург \\ ${ }^{3}$ Научный центр изучения Арктики, Салехард
}

Аннотация. Ископаемые костные и зубные ткани - ценный источник палеонтологической, палеоэкологической и археологической информации. Диагенетические изменения, возникающие практически сразу после смерти и захоронения индивида в среде осадконакопления, могут влиять на корректность извлекаемой из них палеоинформации. В работе на основании исследования структурных характеристик биогенного апатита субфоссильных костей и рогов северного оленя методом рентгенофазового и рентгеноструктурного анализа (параметров и объема элементарной ячейки, степени кристалличности, размеров областей когерентного рассеяния) проведена оценка влияния диагенетических изменений на скелетные ткани. Выявлены тренды фоссилизации в тафономических условиях вечной мерзлоты, а также наименее и наиболее измененные образцы.

Ключевые слова: кости, рога, северный олень, биоапатит, рентгенофазовый и рентгеноструктурный анализ, кристалличность, фоссилизация, диагенез.

\section{Structural features of biogenic apatite of subfossil reindeer skeletal remains (skulls and antlers) from the Arctic zone of Western Siberia}

\author{
Ryanskaya A.D. ${ }^{1}$, Kiseleva D.V. ${ }^{1}$, Pankrushina E.A. ${ }^{1}$, Kosintsev P.A. ${ }^{2}$, Bachura O.P. ${ }^{2}$, Gusev A.V. ${ }^{3}$ \\ ${ }^{1}$ A.N. Zavaritsky Institute of Geology and Geochemistry, Ural Branch of the Russian Academy of Sciences, \\ Ekaterinburg,tosenka2008@gmail.com \\ ${ }^{2}$ Institute of Animal and Plant Ecology, Ural Branch of the Russian Academy of Sciences, Ekaterinburg \\ ${ }^{3}$ Arctic Research Center, Salekhard
}

\begin{abstract}
Fossil bone and dental tissue is a valuable source of paleontological, paleoecological and archaeological information. Diagenetic changes that occur almost immediately after the death and burial of an individual in a sedimentation environment can affect the correctness of the paleoinformation extracted from them. Based on a study of the structural characteristics of biogenic apatite of subfossil reindeer bones and antlers by X-ray phase and X-ray diffraction analysis (unit cell parameters and volume, crystallinity, sizes of coherent scattering regions), the effect of diagenetic changes on skeletal tissues is estimated. The trends of fossilization in the permafrost taphonomic conditions, as well as the least and most altered samples are revealed.

Keywords: bone, antler, reindeer, bioapatite, X-Ray diffraction and structure analysis, crystallinity, fossilization, diagenesis.

\section{Введение}

Одним из основных источников палеонтологической, палеобиологической, палеоэкологической и археологической информации являются твердые ткани костей и зубов. Несмотря на видимую хорошую сохранность, большинство из них подвергается ряду диагенетических изменений, возникающих практически сразу после смерти и захоронения индивида в среде осадконакопления. В ряде случаев такие диагенетические изменения могут влиять на корректность и воспроизводимость извлекаемой из них палеоинформации, а могут и способствовать ее сохранению посредством встраивания различных ионов в кристаллическую решетку и/или перекристаллизации апатита (Elorza et al., 1999). Эти процессы контролируются как внешними микробиологическими и физико-химическими условиями окружающей среды захоронения: химическим составом породы и
\end{abstract}


грунтовых вод, окислительно-восстановительными условиями и др., так и внутренними структурными и гистологическими параметрами самой ткани: размером пор и кристаллитов, содержанием органической фазы и неорганических примесей (Tütken, 2003; Trueman et al., 2004).

Многие работы фокусируются на количественной оценке диагенетического изменения скелетных тканей с использованием структурных и микроструктурных исследований (рентгенофазовый и рентгеноструктурный анализ, инфракрасная и Рамановская спектроскопия) (Lee-Thorp, Sponheimer, 2003; Stathopoulou et al., 2008), которые позволяют получать информацию о кристалличности биогенного апатита, параметрах элементарной ячейки, размерах кристаллитов, анионных и катионных замещениях, примесном составе карбонат-ионов.

Поскольку большинство изменений химического состава происходит на стадии раннего диагенеза в течение $10^{3}-10^{5}$ лет (Tütken, 2003), для изучения этого процесса подходят археологические образцы скелетных тканей из местонахождений железного и бронзового века, которые характеризуются высокой степенью сохранности коллагена и отсутствием перекристаллизации биогенного апатита. Одним из таких археологических памятников является городище Усть-Полуй, расположенное в зоне «вечной» мерзлоты лесотундры (Салехард, Россия). Фаунистические сборы из Усть-Полуя включают обширные коллекции скелетных остатков (костей, зубов и рогов) северного оленя, которые накапливались в течение 500 лет, длительность их нахождения в вечной мерзлоте составляет от 2300 до 1800 лет (Silaev et al., 2017; Losey et al., 2018).

Цель работы - оценка структурных преобразований биогенного апатита при раннем диагенезе в среде вечной мерзлоты на примере субфоссильных костей и рогов северного оленя из Арктической зоны Западной Сибири (святилище Усть-Полуй, Салехард, Россия).

\section{материалы и методы}

Исследовано 17 образцов (Табл. 1) из местонахождения Усть-Полуй: четыре пары череп-рог от четырех особей (УП1-4), два черепа без рогов (УП5-6) и четыре фрагмента сброшенных рогов от различных особей (УП7-10). Для сравнения были исследованы остатки черепа и рогов современного северного оленя (ПУ1) - остатка добычи хищников с Полярного Урала; причем проанализировано как основание, так и верхушка рога. Перед анализом проводили ручное измельчение проб в яшмовых ступках.

Дифрактограммы получены с использованием рентгеновского дифрактометра SHIMADZU XRD-7000: трубка с медным анодом $(\lambda=1.5406 \AA)$, диапазон брэгговских углов $2 \Theta 3-70^{\circ}$, скорость съемки $1 \%$ мин, напряжение 40 кВ, ток 30 мА. Количественный полнопрофильный рентгенофазовый анализ проведен методом Ритвельда с помощью программы SiroQuant (Sietronics, Австралия) в соответствии с работой (Рянская и др., 2015).

\section{Результаты и обсуждение}

Дифрактограммы исследованных образцов характеризуются наличием уширенных плохоразрешенных пиков и значительного фона, свидетельствующих о наличии микронапряжений и аморфной или слабоокристаллизованной фазы, что, в целом, характерно для современной и субфоссильной костной ткани. Фазово-минеральный состав костей и рогов оленей, а также уточненные методом Ритвельда параметры элементарной ячейки биогенного апатита приведены в таблице 1. Образцы состоят, главным образом, из гидроксилапатита (96.3-100 \%) с незначительной примесью кварца (0-6.4 \%), наличие которого может быть обусловлено попаданием из вмещающих супесчаных отложений. Ткани современного оленя на 100 \% представлены гидроксилапатитом.

Анализ параметров элементарной ячейки биоапатита выявил линейную зависимость между параметрами $a$ и $c$ и ее объемом. Почти все ткани рогов по параметру $а$ укладываются в диапазон между (карбонат-)гидроксилапатитом и фторапатитом, с линейным увеличением объема ячейки от фторапатита к гидроксилапатиту. При этом черепа УП6 и УП2 ближе к гидроксилапатиту; рога занимают промежуточное положение. Исключение составляет основание рога современного оленя ПУ1, которое характеризуется минимальными значениями а $=9.36 \AA$ и объема ячейки $\mathrm{V}=518.6 \AA^{3}$, которые ближе к карбонат-фторапатиту (франколиту). 
В упрощенном виде выявленный тренд можно объяснить совокупным воздействием несколь-

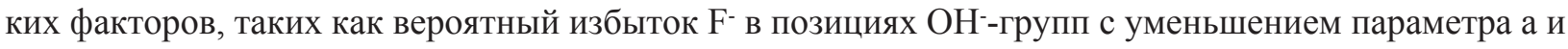
объема ячейки (характерно для исходно более пористых рогов, более активно промываемых грунтовыми поровыми водами), а также уменьшение и/или перераспределение карбонатных групп А и В типа (замещающих ОН и фосфатные группы, соответственно) с уменьшением параметра с и объема ячейки апатита (Stathopoulou et al., 2008; Lee-Thorp, Sponheimer, 2003).

Таблица 1. Минеральный состав, уточненные параметры элементарной ячейки, индекс кристалличности (CI) и размеры кристаллитов биогенного апатита костей и рогов северного оленя.

Table 1. Mineral composition, refined unit cell parameters, crystallinity index (CI) and crystallite dimensions of biogenic apatite from reindeer bones and antlers.

\begin{tabular}{|c|c|c|c|c|c|c|c|c|c|}
\hline \multirow[t]{2}{*}{ № } & \multirow[t]{2}{*}{ Шифр пробы } & \multirow[t]{2}{*}{ Ткань } & \multirow[t]{2}{*}{ Фазовый состав } & \multicolumn{2}{|c|}{$\begin{array}{c}\text { Параметры } \\
\text { элементарной } \\
\text { ячейки, } \AA\end{array}$} & \multirow[t]{2}{*}{$\mathrm{V}_{\text {cell }}, \AA^{3}$} & \multirow[t]{2}{*}{ CI } & \multicolumn{2}{|c|}{$\begin{array}{c}\text { Размеры } \\
\text { кристаллитов, нм }\end{array}$} \\
\hline & & & & $a, b$ & $\mathrm{c}$ & & & Длина & Ширина \\
\hline 1 & УП1 736/4898_cr & Череп & HAp $-100 \%$ & 9.4417 & 6.8747 & 530.7 & 0.62 & 29.3 & 7.6 \\
\hline 2 & $\begin{array}{c}\text { УП1 } \\
736 / 4898 \text { _cor }\end{array}$ & Рог & $\begin{array}{c}\text { HAp }-99 \% \\
Q-1 \%\end{array}$ & 9.4075 & 6.8575 & 525.6 & 0.63 & 28.9 & 7.1 \\
\hline 3 & $\begin{array}{c}\text { УП2 } \\
\text { 736/21957_cr }\end{array}$ & Череп & $\begin{array}{c}\text { HAp }-98.4 \% \\
Q-1.6 \%\end{array}$ & 9.4348 & 6.8801 & 530.4 & 0.60 & 33.0 & 8.3 \\
\hline 4 & $\begin{array}{c}\text { УП2 } \\
\text { 736/21957_cor }\end{array}$ & Рог & $\begin{array}{c}\text { HAp }-97.6 \% \\
Q-2.4 \%\end{array}$ & 9.4151 & 6.8672 & 527.2 & 0.59 & 33.4 & 9.3 \\
\hline 5 & $\begin{array}{c}\text { УП3 } \\
736 / 6524 \_c r\end{array}$ & Череп & HAp $-100 \%$ & 9.4509 & 6.8851 & 532.6 & 0.62 & 30.1 & 11.6 \\
\hline 6 & $\begin{array}{c}\text { УП3 } \\
\text { 736/6524_cor }\end{array}$ & Рог & HAp $-100 \%$ & 9.4263 & 6.8680 & 528.5 & 0.61 & 32.2 & 9.2 \\
\hline 7 & $\begin{array}{c}\text { УП4 } \\
\text { 736/6523_cr }\end{array}$ & Череп & $\begin{array}{c}\text { HAp }-98.2 \% \\
\text { Q }-1.8 \%\end{array}$ & 9.4071 & 6.8642 & 526.1 & 0.62 & 31.7 & 9.1 \\
\hline 8 & $\begin{array}{c}\text { УП4 } \\
736 / 6523 \text { _cor }\end{array}$ & Рог & $\begin{array}{c}\text { HAp }-98 \% \\
Q-2 \%\end{array}$ & 9.4203 & 6.8669 & 527.7 & 0.60 & 32.7 & 7.5 \\
\hline 9 & $\begin{array}{c}\text { УП5 } \\
736 / 4899 \text { cr }\end{array}$ & Череп & $\begin{array}{c}\text { HAp }-95.4 \% \\
Q-4.6 \%\end{array}$ & 9.3935 & 6.8677 & 524.8 & 0.67 & 29.3 & 9.2 \\
\hline 10 & $\begin{array}{c}\text { УП6 } \\
\text { 736/21326_cr }\end{array}$ & Череп & $\begin{array}{c}\text { HAp }-93.6 \% \\
Q-6.4 \%\end{array}$ & 9.4253 & 6.8821 & 529.5 & 0.38 & 52.0 & 12.9 \\
\hline 11 & $\begin{array}{c}\text { УП7 } \\
\text { 736/31996 cor }\end{array}$ & Рог & $\begin{array}{c}\text { HAp }-96.5 \% \\
Q-3.5 \%\end{array}$ & 9.4421 & 6.8745 & 530.8 & 0.56 & 35.2 & 9.0 \\
\hline 12 & $\begin{array}{c}\text { УП8 } \\
\text { 736/3977_cor }\end{array}$ & Рог & $\begin{array}{c}\text { HAp }-97.2 \% \\
Q-2.8 \%\end{array}$ & 9.4155 & 6.8657 & 527.1 & 0.56 & 34.8 & 10.1 \\
\hline 13 & $\begin{array}{c}\text { УП9 } \\
\text { 736/6411_cor }\end{array}$ & Рог & HAp $-100 \%$ & 9.4306 & 6.8728 & 529.4 & 0.61 & 32.4 & 7.6 \\
\hline 14 & $\begin{array}{c}\text { УП10 } \\
\text { 736/6507_cor }\end{array}$ & Рог & HAp - $100 \%$ & 9.4204 & 6.8741 & 528.3 & 0.64 & 29.3 & 10.4 \\
\hline 15 & $\begin{array}{c}\text { ПУ1 } \\
9004 / 1889 \text { cr }\end{array}$ & Череп & HAp $-100 \%$ & 9.4465 & 6.8926 & 532.7 & 0.64 & 30.4 & 8.9 \\
\hline 16 & $\begin{array}{c}\text { ПУ1 } \\
\text { 9004/1889_cor_ } \\
\text { ba }\end{array}$ & $\begin{array}{c}\text { Рог осно- } \\
\text { вание }\end{array}$ & HAp $-100 \%$ & 9.3669 & 6.8252 & 518.6 & 0.67 & 28.3 & 10.3 \\
\hline 17 & $\begin{array}{c}\text { ПУ1 } \\
\text { 9004/1889_cortip }\end{array}$ & $\begin{array}{c}\text { Рог вер- } \\
\text { хушка }\end{array}$ & HAp $-100 \%$ & 9.4311 & 6.8656 & 528.9 & 0.82 & 22.8 & 11.0 \\
\hline
\end{tabular}

Под кристалличностью понимается степень упорядоченности апатитовой фазы на атомном уровне, следовательно, анализ уширения линий на дифрактограммах может быть использован для простейшей оценки кристалличности в апатите костной ткани. Следуя (Elorza et al., 1999), мы pacсчитали индексы кристалличности (CI, crystallinity index) как полную ширину на уровне половинной амплитуды (FWHM, full width at half maximum) рефлекса апатита 002, выраженной в градусах $2 \theta$. 
Полученные значения СI (табл. 1) несколько больше, чем типичные для современных: различными исследователями указываются диапазоны 0.39-0.48 (Elorza et al., 1999) и 0.32-0.39, а также 0.41-0.54 для свежей костной ткани млекопитающих (Sillen, 1989). Тем не менее, значения индекса кристалличности апатита субфоссильных образцов значительно больше, чем в костной ткани пермской парарептилии (0.266-0.250, Ryanskaya et al., 2019), в кости юрского сейсмозавра (0.15, Chipera \& Bish, 1991) и в мезозойских костных остатках (0.2-0.3, Elorza et al., 1999), что не противоречит современным представлениям об увеличении кристалличности (уменьшении индекса кристалличности) при фоссилизации.

Основываясь на гексагональной структуре апатита, нами были рассчитаны средние размеры области когерентного рассеяния (кристаллитов): длина с использованием рефлекса апатита 002 и ширина с использованием рефлекса 310 (Dumont et al., 2011; Ryanskaya et al., 2019) по формуле Шерpepa:

$$
\mathrm{t}=\mathrm{K} \lambda /(\mathrm{FWHM} \cdot \cos \theta)
$$

где $\mathrm{t}$ - размер кристаллита, нм; $\mathrm{K}$ - постоянная Шеррера, $\mathrm{K}=2$ для рефлекса 002 и $\mathrm{K}=1$ для рефлекса 310 (Dumont et al., 2011); $\lambda$ - длина волны используемого излучения, $\AA$ (1.5406 $\AA$ для $\mathrm{Cu} \mathrm{K} \alpha$ ); FWHM - полная ширина на уровне половинной амплитуды измеренного рефлекса, радианы; $\theta$ - половина угла дифракции для измеренного рефлекса, градусы.

Рассчитанные размеры кристаллитов (нм) приведены в таблице 1. Они составляют 28.9-52.0 (среднее 33.2) нм в длину и 7.1-12.9 (среднее 9.2) нм в ширину для субфоссильных образцов и 22.8-30.4 (среднее 27.2) нм в длину и 8.9-11.0 (среднее 10.1) нм в ширину для современных тканей. Это в целом соответствует средней длине кристаллитов современных костей млекопитающих около 40 нм (Trueman et al., 2004), а также субфоссильных образцов костной ткани бизона и лошади 10×15 нм (Dumont et al., 2011), и кости современного лося 20.6×8.3 нм (Chipera \& Bish, 1991).

В целом, полученные размеры областей когерентного рассеяния (кристаллитов) апатита скелетных субфоссильных и современных тканей, а также индексов кристалличности не противоречат литературным данным. Однако, образец черепа УПб выбивается из общей картины: он имеет самый низкий индекс кристалличности $\mathrm{CI}=0.38$, и, соответственно, самое высокое значение размеров кристаллитов 52 нм в направлении (002), что может свидетельствовать о большей степени его диагенетических преобразований по сравнению с остальными. Авторами (Reiche et al., 2002) отмечается факт увеличения длин кристаллитов (до более чем 100 нм) апатита субфоссильных костей млекопитающих, захороненных в особых геохимических обстановках, например, на затапливаемых территориях; при этом процесс диагенетического изменения размеров кристаллитов может иметь два объяснения: вымывание мелких кристаллитов либо растворение и переосаждение мелких кристаллитов, приводящее к общему увеличению среднего размера. Следует отметить также, что образец УП6 имеет в своем составе наибольшее количество примесного кварца, что может косвенно свидетельствовать о большей пористости костной ткани.

Таким образом, для отличающихся по структурным параметрам черепов УП2, УП4, УП5 и УП6 можно предположить наибольшее влияние диагенетических изменений в результате отличных от основной массы условий фоссилизации, вероятно способствовавших потере органического вещества и/или карбонатных группировок биоапатита в большей мере, чем для остальных костей и рогов. Для всех рогов также характерны диагенетические изменения различной степени; при этом УП7, УП9 и верхушка рога ПУ1 наименее изменены. Следовательно, они будут сохранять скорее параметры среды захоронения, чем прижизненные характеристики организма.

\section{Выводы}

Субфоссильные костные ткани (черепа) и рога северного оленя из Усть-Полуя характеризуются наличием микронапряжений и аморфной или слабоокристаллизованной минеральной фазы гидроскилапатита, в целом присущих современной костной ткани. Тем не менее, в них обнаружены раннедиагенетические изменения различной степени (изменение индекса кристалличности, параметров и объема элементарной ячейки, уменьшение и перераспределение карбонатных замещений, из- 
менение размеров кристаллитов). Наименее измененные образцы (современная ткань черепа оленя с Полярного Урала, УП1 и УПЗ) могут быть использованы для извлечения палеосигнала, а в остальных, наиболее измененных, образцах он может частично или полностью перекрываться характеристиками среды захоронения в супесчаных отложениях на территории Усть-Полуя.

Работа выполнена в ЦКП УрО РАН «Геоаналитик» и поддержана грантом РФФИ №18-35-00462.

\section{Литература}

1. Рянская А.Д., Щапова Ю.В., Гуляева Т.Я., Галахова О.Л., Петрищева В.Г., Горбунова Н.П., Татаринова Л.А. Полнопрофильный рентгенодифракционный анализ фазово-минерального состава пород-коллекторов нефти и газа с использованием программы SiroQuant (на примере искусственных смесей) // ЕЖЕГОДНИК-2014. Тр. ИГГ УрО РАН. 2015. № 162. С. 267-275.

2. Chipera S.J. and Bish D.L. Applications of X-ray diffraction crystallite size/strain analysis to Seismosaurus dinosaur bone // Advances in X-ray Analysis. 1990. V. 34. P. 473-482.

3. Elorza J., Astibia H., Murelaga X., Pereda-Suberbiola X. Francolite as a diagenetic mineral in dinosaur and other Upper Cretaceous reptile bones (Lano, Iberian Peninsula): microstructural, petrological and geochemical features // Cretaceous Research. 1999. V.20. P. 169-187. DOI: 10.1006/cres.1999.0144.

4. Lee-Thorp J., Sponheimer M. Three case studies used to reassess the reliability of fossil bone and enamel isotope signals for paleodietary studies // Journal of Anthropological Archaeology. 2003. V. 22. P. 208-216. DOI: $10.1006 /$ jasc.1998.0293.

5. Losey R.J., Fleming L.S., Nomokonova T., Gusev A.V., Fedorova N.V., Garvie-Lok S., Bachura O.P., Kosintsev P.A., Sablin M.V. Human and Dog consumption of Fish on the Lower Ob River of Siberia: evidence for a major Freshwater Reservoir Effect at the Ust'-Polui site // Radiocarbon. 2018. V. 60. No. 1. P. 239-260. DOI: $10.1017 /$ RDC.2017.77.

6. Reiche I., Vignaud C., Menu M. The crystallinity of ancient bone and dentine: new insights by transmission electron microscopy // Archaeometry. 2002. V. 44 (3). P. 447-459. DOI: 10.1111/1475-4754.00077.

7. Ryanskaya A.D., Kiseleva D.V., Shilovsky O.P. \& Shagalov E.S. XRD study of the Permian fossil bone tissue // Powder Diffraction. 2019. V. 34(S1). S14-S17. DOI: 10.1017/S0885715619000174.

8. $\quad$ Silaev V.I., Parshukova M.N., Slepchenko S.M., Smoleva I.V., Kiseleva D.V., Shanina S.N., Tropnikov E.A., Khazov A.F. Ust-Poluyskoye site-sanctuary: the experience of mineralogical and geochemical studies of human bone remains. Syktyvkar. 2017. 68 p.

9. Sillen A. Diagenesis of the inorganic phase of compact bone. In: The chemistry of prehistoric human bone (ed. Price T. D.). Cambridge University Press, Cambridge: 1989. P. 211-229.

10. Stathopoulou E.T., Psycharis V., Chryssikos G.D., Gionis V., Theodorou G. Bone diagenesis: New data from infrared spectroscopy and X-ray diffraction // Palaeogeography, Palaeoclimatology, Palaeoecology. 2008. V. 266. P. 168-174. DOI:10.1016/j.palaeo.2008.03.022.

11. Trueman C.N.G., Behrensmeyer A.K., Tuross N., Weiner S. Mineralogical and compositional changes in bones exposed on soil surfaces in Amboseli National Park, Kenya: diagenetic mechanisms and the role of sediment pore fluids // Journal of Archaeological Science. 2004. V. 31. P. 721-739. DOI:10.1016/j.jas.2003.11.003.

12. Tütken T. Die Bedeutung der Knochenfrühdiagenese für die Erhaltungsfähigkeit in vivo erworbener Elementund Isotopenzusammensetzungen in fossilen Knochen. Universität Tübingen. 2003. 343 p. Online dissertation: $<$ http://tobias-lib.unituebingen. de/volltexte/2003/962/>. 